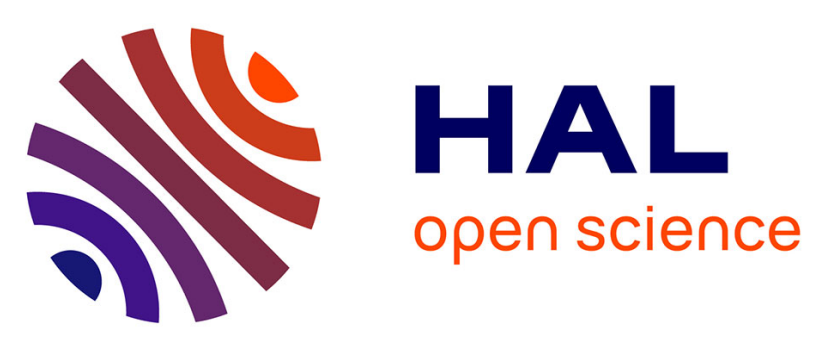

\title{
Research on Agent-Based Bee Product Traceability Platform and Barcode System
}

\author{
Shengping Liu, Yeping Zhu, Shijuan Li
}

\section{To cite this version:}

Shengping Liu, Yeping Zhu, Shijuan Li. Research on Agent-Based Bee Product Traceability Platform and Barcode System. 5th Computer and Computing Technologies in Agriculture (CCTA), Oct 2011, Beijing, China. pp.445-454, 10.1007/978-3-642-27281-3_50 . hal-01351845

\section{HAL Id: hal-01351845 \\ https://hal.inria.fr/hal-01351845}

Submitted on 4 Aug 2016

HAL is a multi-disciplinary open access archive for the deposit and dissemination of scientific research documents, whether they are published or not. The documents may come from teaching and research institutions in France or abroad, or from public or private research centers.
L'archive ouverte pluridisciplinaire HAL, est destinée au dépôt et à la diffusion de documents scientifiques de niveau recherche, publiés ou non, émanant des établissements d'enseignement et de recherche français ou étrangers, des laboratoires publics ou privés. 


\title{
Research on Agent-based Bee Product Traceability Platform and Barcode system
}

\author{
Shengping Liu ${ }^{1,2}$, Yeping $\mathrm{Zhu}{ }^{1,2}$, Shijuan $\mathrm{Li}^{1}$, \\ ${ }^{1}$ Agricultural Information Institute, Chinese Academy of Agricultural Sciences, \\ Beijing, China, P.R. China, 100081, \\ ${ }^{2}$ Key Laboratory of Digital Agricultural Early-warning Technology, Ministry of Agriculture, \\ The People's Republic of China, Beijing, P.R. China, 100081, spliu@caas.net.cn
}

\begin{abstract}
Establishing agricultural product quality safety traceability platform and barcode system have become a worldwide trend. Bee product traceability platform that can be used to identify all aspects from farm to table has been laid out based on China law and global standards. An integrated bee product traceability system which involving all of the process along the supply chain can be applied to increase consumer confidence of bee products by making traceability data accessible to the consumer. In this bee product traceability platform, barcode system is of enormous significance and due to its applications in the all tracing stage of platform, standard barcode system architecture and infrastructure become very important.

In this paper, we study safety situation of bee product quality, research status of bee product traceability and barcode system. We construct bee product traceability platform by adopting agent technology, build barcode system by adopting GS1 global traceability standard as well as realize standardization barcoding of bee product data content during four links: materials collection, purchase, processing and sales. Applying barcode system and traceability platform in bee products distribution process can realize bee products tracking and tracing, offer strong guarantee for Chinese bee product quality safety and improve competitiveness of bee products in international market.
\end{abstract}

Keywords: bee product, traceability system, barcode

\section{Introduction}

\subsection{Current Situation of Bee Products Quality Safety}

The annual capacity of honey is about 293,000 tons at present in China, which including royal 3,000 tons jelly honey bee, 3,000 tons pollen and 350 tons propolis, the total output value of honey is about 8 billion RMB and annual export value is about $\$ 133$ million [1]. As advantage products in our country, bee products have important function for export, human health. Bee products quality safety problems are not only in relation to the bee industry development, but also in relation to consumer 
safety and the improvement of bees' international competitiveness. Consequently, Study the quality safety problems of bee products has important meaning to promote bee industry development [2].

In recent years the rapid growth of bee products processing industry, and meanwhile an extension of the industrial chain and bees industry itself exists many factors that caused various quality problems of bee products, which directly affect bee products export, and also shock Chinese domestic market. EU and some countries took trade barriers like forbid export and stop selling to Chinese honey in 2002 [3], which made great loss to Chinese beekeeping industry, seriously impacted normal development of beekeeping industry, and also caused Chinese government departments to pay attention to bee products quality problems. The key problem of bee products quality safety is doping fake and drug residue in China, and these kinds of problems have not been able to get fundamental solution [4]. The production and purchase link of Chinese bees industry especially the raw honey are loose management, small scale, and bad degree of organization, but effective supervision need reliable technical means, so the demand for bee products' quality safety traceability system is more pressing.

\subsection{Current Situation of Bee Products' Traceability System Research}

Bee products are particular agricultural products, so all countries in the world pay very attention on the quality safety, and the traceability research of bee products is actively developing at home and abroad.

On the law level, EU Traceability Regulations-Regulation (EC) No 178/2002 article 18 Traceability, trade operator must ensure product's traceability. Our country "Food Safety Law" and "Produce Quality Safety Law" also provide legal protection for the implementation of traceability system on legal level [5].

EU sixth framework program put forward the standard of record information during honey sales chain traceability process, the content of record is to achieve good traceability purpose, and detailed information that should be recorded in honey sales chain. Greece and Hungary proposed joint and implemented "Trace Honey" project, Hungary-Greece food network traceability and transparency research raised pilot research for honey production and processing and sales chain management. Argentina Agriculture Food Sanitation and Quality Bureau(SENASA) put forward honey refining room is the core of the traceability system; Refining room, beekeeping producers and honey barrels are required to pass through SENASA registered commercial Apitrack traceability system has been promoted in many countries [6-9]. Ontario, Canada agricultural food and rural affairs traceability pilot plan, also including bee products.

Due to long industry chain, no specified industry standard and many influencing factors for quality safety, currently research work of Chinese bee products quality safety tracing system is mainly conducted by Bee Research Institution and Agriculture Information Research Institution of Chinese Academy of Agricultural Science [10].

This article, through the analysis of the Chinese bee products quality safety and bar code system research status, proposes to introduce modern information technology 
into bee industry in order to realize whole process trace of bee products, uses GS1 standard to set up bee products traceability bar code system, and constructs bee products trace platform which is based on Agent according to industry characteristics.

\section{Research Status of Barcode System}

Unified code system is the foundation of launching bee product traceability and the premise of information exchange and process in trace process. Bee product traceability barcode must have some standard principles: uniqueness, stability, versatility, extensibility and applicability. In trace process trace key points mainly include raw honey gathering barcode, honey purchase barcode, process barcode and the products barcode. All these key elements must be bar-code uniformly and standardly so that information of different trace link is unique identification. In this research GS1 system is used for realizing uniform and standard barcode of bee product.

\subsection{GS1 System}

The GS1 System is an integrated system of global standards that provides with accurate identification and communication of information regarding products, assets, services and locations. It is the most widely implemented supply chain standards system in the world. It is the foundation of a wide range of efficiency-building supply chain applications and solutions and is composed of the following two areas: GS1 barcodes and GS1 traceability.

GS1 unified label system performs an important function for physical implementation of agricultural products barcode, especially for agricultural products' standardized management in logistics links. GS1 system has been widely used in the logistics and retai industry of the global supply chain. It reduces system operation cost and avoids causing supply chain's uncertainty. Adopting global unified identification system can realize rapid and accurate seamless links between Information flow and material flow.

Table 1. Symbols and abbreviations. Table 1 shows symbol and abbreviation in GS1 system.

\begin{tabular}{ll}
\hline Symbol & Abbreviation \\
\hline AI & GS1 system Application Identifier \\
GLN & GS1 system Global Location Number \\
GMP & Good Manufacturing Practice \\
GS1 & Global Solution 1 \\
GS1 system & Unique global identification system \\
GTIN & GS1 system Global Trade Item Number \\
ID & Identification \\
ISO & The international Organization for Standardization \\
n2 or n14,etc & GS1 identifier numbers consisting for 2 or 14, etc digits \\
SSCC & GS1 system Serial Shipping Container Code \\
\hline
\end{tabular}




\subsection{Barcode Research Situation of Agricultural Product Traceability System}

At present agricultural product traceability systems are widely developing in at home and abroad. Zheng has analyzed traceability chain of cooking oil products and designed cooking oil product system based on batch management, meanwhile, zheng proposed barcoding rules of core link which included origin, process and final product [11-12]. Liu has encoded Fruit and vegetable products. According to characteristic of lamb industry chain as well as actual information level of lamb manufacturing enterprises, Wang has developed lamb barcode system. Xiong has realized pork quality safety traceability. Deng has studied producing area code of agricultural product, divided tea planting area and uniformly encoded tea. Sheng has developed beef traceability barcode system.

In general most research organizations have carried out traceability barcode system research according to pork, beef, lamb, grain and oil, fruit and vegetable [13]. However, research about bee product traceability barcode system has not been reported. Developing bee product barcode system is a difficult task because that collection source of bee product scattered and honey adulteration are widely spread.

\section{Agent-based Bee Products Traceability Platform}

Agent theory and technology, as a part of distributed artificial intelligence, has developed rapidly since it arose from 1970s, it is a popular direction of artificial intelligence now [15-16]. The researches on agent have received a great deal of attention because of its characteristics, such as autonomy, collaboration, intelligence, mobility, and the potential to build complex systems [17]. In recent years agent theory and technology research have been rapidly developed, many studies, which including agent-oriented development language, development framework, and method, decision support system and collaboration work model, make good progress. Agent and multiagent system technology have given us a new way to look at distributed systems and provided a path for more robust intelligent applications [18].

In food processing, the term traceability refers to the recording through means of barcodes \& other tracking media, all movement of product and steps within the production process. One of the key reasons is in instances where an issue of contamination arises, and a recall is required. Where traceability has been closely adhered to, it is possible to identify, by precise date $\&$ location which goods must be recalled, and which are safe, potentially saving millions of dollars in the recall process. Traceability within the food processing industry is also utilized to identify key high production \& quality areas of a business, versus those of low return, and where points in the production process may be improved.

This research has built agent-based bee products traceability platform which based on agent theory and quality tracing method. In figure 1, on account of the characters of independent interaction among the key control points in the bee product traceability platform, a development platform and multiple principal body system of bee product traceability are designed with agent-based method, the platform agent is adopted to perform data acquisition, bar code manufacturing, data inquiry, 
information surveillance and task management; and task management agent is employed to realize bee farm management, supplier management, processing management and sales management. And data acquisition system developed in this paper is managed by data acquisition agent, the data thus obtained is transmitted via ACL language to the platform management agent to achieve data sharing and surveillance, as well as to fulfill the purpose of bee product information traceability.

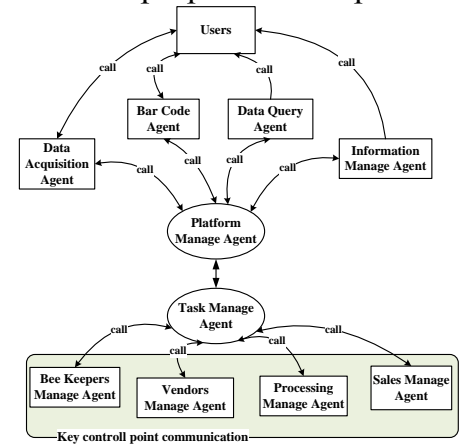

Fig. 1. Agent-based Bee products traceability platform.

\section{Barcode System of Bee Product Traceability}

Bee product traceability platform mainly consists of the following flows (Figure 2): tracking process (clockwise direction) begins from the origin of honeybee, covering a couple of key control points like place of production, distributor, processing plant and seller, so raw material purchase process, honeybee processing process, product selling process and retail process are traced. Tracing process (counter-clockwise direction) is traced back from customers, including the tracing of selling, production, raw material and place of origin. By means of the bee product traceability platform, tracking and tracing of several key control points like place of origin, distributor, processing plant, seller and customer can be realized, and bee product quality safety can be safeguarded.

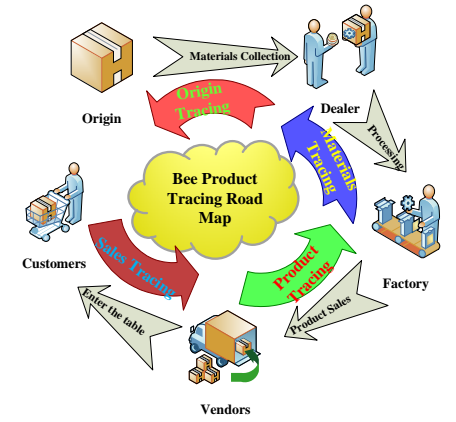

Fig. 2. Bee product traceability road map. 
In various links of bee products tracking and tracing, GS1 system was used for barcoding and providing uniform code standards. Standardization bar code can provide accurate, safe and reliable traceability information.

Table 2. Barcode system information of bee product supply chain. Table 2 shows information exchange process of bee products traceability links.

\begin{tabular}{|c|l|l|l|l|}
\hline Supply chain & \multicolumn{1}{|c|}{ Gathering } & \multicolumn{1}{|c|}{ Purchase } & Process & \\
\hline \multirow{2}{*}{ Diagram } & &
\end{tabular}

\subsection{Honey Gathering Process}

When bee farmers finished gathering honey in apiary, they attach different apiary honey traceability label to different honey barrels. Table 3 shows barcode information and label text information in apiary traceability links. And Figure 3 indicates apiary traceability barcode label which including necessary text and barcode. The traceability information can be used in information exchange between apiary and purchase trader or between apiary and processing factory.

Table 3. Barcode and information of gathering process.

\begin{tabular}{|l|l|l|l|c|c|}
\hline \multirow{2}{*}{ Data content } & \multirow{2}{*}{ Data name } & \multirow{2}{*}{ UCC/EAN-128 } & \multirow{2}{*}{ Example } & Categorisation \\
\hline Gathering process & & \multicolumn{2}{l|}{ Shall } & may \\
\hline $\begin{array}{l}\text { Traceability code of gathering } \\
\text { honey }\end{array}$ & $\begin{array}{l}\text { PROCESSOR+ } \\
\text { PACAK DATE + LOT }\end{array}$ & $\begin{array}{l}\mathrm{AI}(7030)+\mathrm{AI}(13 \\
)+\mathrm{AI}(10)\end{array}$ & $\begin{array}{l}(7030) 156510183010 \\
01(13) 080527(10) 011\end{array}$ & $\checkmark$ & \\
\hline Apiary code & PROCESSOR & $\mathrm{AI}(7030)$ & $\mathrm{n} 4+\mathrm{n} 3+\mathrm{an} . .27$ & & $\checkmark$ \\
\hline Production date & PACK DATE & $\mathrm{AI}(13)$ & $\mathrm{n} 2+\mathrm{n} 6$ & & $\checkmark$ \\
\hline Lot number & LOT & $\mathrm{AI}(10)$ & $\mathrm{n} 2+\mathrm{an} . .20$ & & $\checkmark$ \\
\hline Global location number of honey & GLN & $\mathrm{AI}(414)$ & $\mathrm{n} 3+\mathrm{n} 13$ & $\checkmark$ \\
\hline Honey kinds & REF.TO SOURCE & $\mathrm{AI}(251)$ & $\mathrm{n} 3+\mathrm{an} \ldots 30$ & $\checkmark$ \\
\hline Honey weight & NET WEIGHT & $\mathrm{AI}(3100)$ & $\mathrm{n} 4+\mathrm{n} 6$ & & $\checkmark$ \\
\hline
\end{tabular}




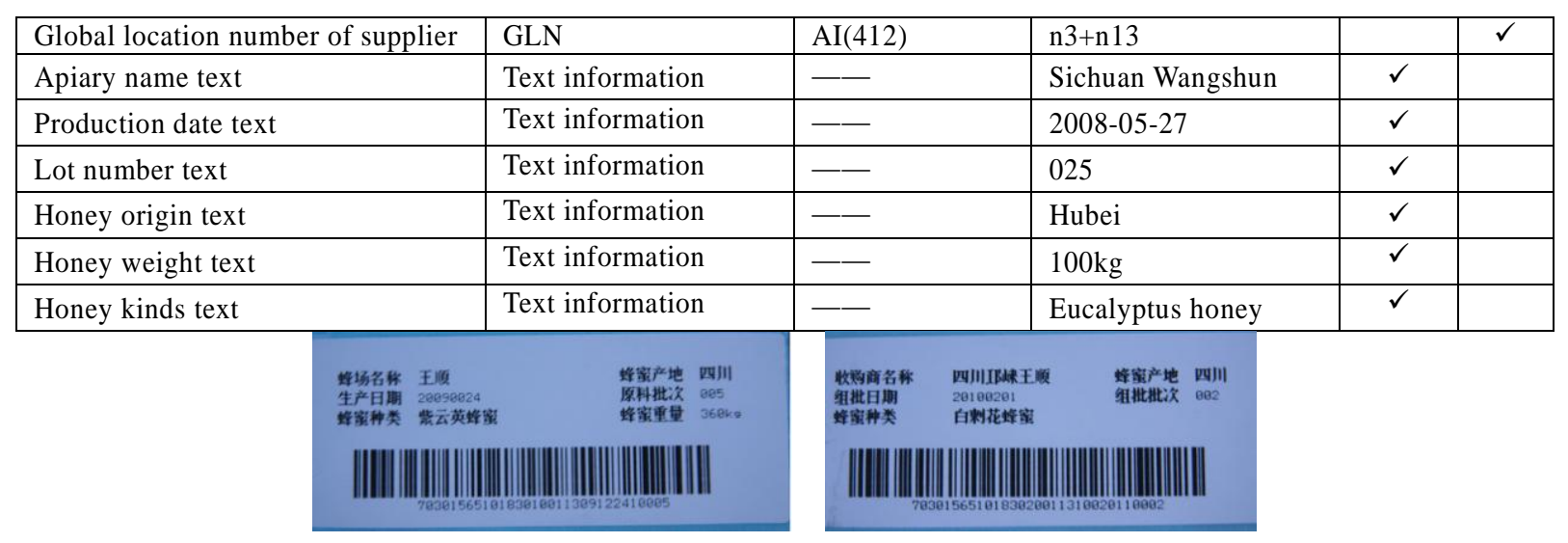

Fig. 3. Honey gathering label and Honey purchase label.

\subsection{Purchase Process}

When purchase traders buy honey from bee keeper, they need to attach purchase traceability label to their honey barrels. Table 4 displays barcode information and label text information in purchase traceability link. And Figure 3 shows purchase traceability barcode label which consists of necessary text and barcode. The traceability information can be used in information exchange between purchase trader and processing factory.

Table 4. Barcode and information of purchase process.

\begin{tabular}{|c|c|c|c|c|c|}
\hline \multirow{2}{*}{ Data content } & \multirow{2}{*}{ Data name } & \multirow{2}{*}{ UCC/EAN-128 } & \multirow{2}{*}{ Example } & \multicolumn{2}{|c|}{ Categorisation } \\
\hline & & & & Shall & may \\
\hline \multicolumn{6}{|l|}{ Purchase process } \\
\hline $\begin{array}{l}\text { Traceability code of purchase } \\
\text { honey }\end{array}$ & $\begin{array}{l}\text { PROCESSOR+ } \\
\text { PACAK DATE + LOT }\end{array}$ & $\begin{array}{l}\mathrm{AI}(7030)+\mathrm{AI}(13 \\
)+\mathrm{AI}(10)\end{array}$ & $\begin{array}{l}(7030) 156420804020 \\
01(13) 090621(10) 025\end{array}$ & $\checkmark$ & \\
\hline Purchase code & PROCESSOR & $\mathrm{AI}(7030)$ & $\mathrm{n} 4+\mathrm{n} 3+\mathrm{an} \ldots 27$ & & $\checkmark$ \\
\hline Production date & PACK DATE & $\mathrm{AI}(13)$ & $\mathrm{n} 2+\mathrm{n} 6$ & & $\checkmark$ \\
\hline Lot number & LOT & $\mathrm{AI}(10)$ & $\mathrm{n} 2+\mathrm{an} \ldots 20$ & & $\checkmark$ \\
\hline Global location number of honey & GLN & $\mathrm{AI}(414)$ & $\mathrm{n} 3+\mathrm{n} 13$ & & $\checkmark$ \\
\hline Honey kinds & REF.TO SOURCE & $\mathrm{AI}(251)$ & $\mathrm{n} 3+\mathrm{an} \ldots 30$ & & $\checkmark$ \\
\hline Honey weight & NET WEIGHT & $\mathrm{AI}(3100)$ & n4+n6 & & $\checkmark$ \\
\hline Global location number of supplier & GLN & $\mathrm{AI}(412)$ & $\mathrm{n} 3+\mathrm{n} 13$ & & $\checkmark$ \\
\hline Purchase trader name text & Text information & -1 & Hubei Heqingbiao & $\checkmark$ & \\
\hline Package date text & Text information & -— & $2009-09-13$ & $\checkmark$ & \\
\hline Lot number text & Text information & - & 025 & $\checkmark$ & \\
\hline Honey origin text & Text information & - & Hubei & $\checkmark$ & \\
\hline Honey weight text & Text information & - & $100 \mathrm{~kg}$ & $\checkmark$ & \\
\hline Honey kinds text & Text information & -— & Cole honey & $\checkmark$ & \\
\hline
\end{tabular}




\subsection{Processing Process}

Processors package honey products according to consuming unit or distribution unit as well as transport products through highway, aviation or sea transportation. Table 5 presents barcode information and label text information in process traceability link. And Figure 4 shows process traceability barcode label which is made of necessary text and barcode. The traceability information can be used in information exchange between processing factory and seller.

Table 5. Barcode and information of processing process.

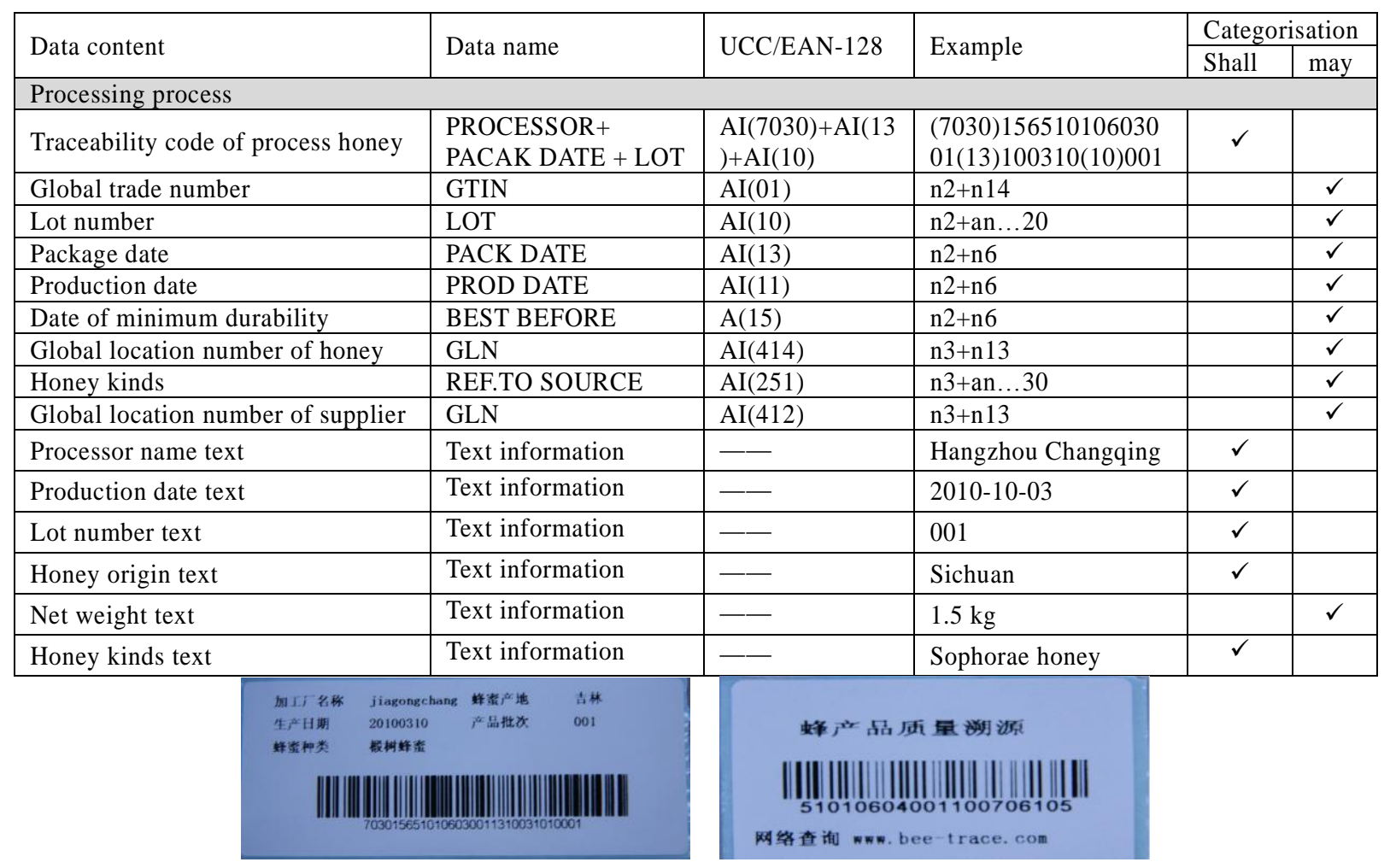

Fig. 4. Product process label and Commodity sale label.

\subsection{Sale Process}

When dealer affords product to consumer necessary traceability information includes bar code for commodity and traceability code. Table 6 displays barcode information and label text information in sale traceability link. And Figure 4 demonstrates shows sale traceability barcode label which composed by necessary text and barcode. 
Through querying traceability barcode in website, consumer can get all traceability information of bee product.

Table 6. Barcode and information of sale process.

\begin{tabular}{|l|l|l|l|c|c|}
\hline \multirow{2}{*}{ Data content } & \multirow{2}{*}{ Data name } & \multirow{2}{*}{ EAN/UPC } & \multirow{2}{*}{ Example } & \multicolumn{2}{l|}{ Categorisation } \\
\hline Sale link & & \multicolumn{5}{l}{ Shall } & may \\
\hline Bar code for commodity & EAN-13 & EAN/UCC-13 & 6901234567892 & $\checkmark$ & \\
\hline Commodity traceability barcode & $\begin{array}{l}\text { PROCESSOR+PAC } \\
\text { AK DATE + LOT }\end{array}$ & EAN-128 & 51010604001100706105 & $\checkmark$ & \\
\hline Processor name text & Text information & - & Hangzhou Changqing & & $\checkmark$ \\
\hline Production date text & Text information & - & $2010-07-06$ & 105 & $\checkmark$ \\
\hline Lot number text & Text information & - & Sichuan & & $\checkmark$ \\
\hline Honey origin text & Text information & - & 1.5 kg & & $\checkmark$ \\
\hline Net weight text & Text information & - & Sophorae honey & & $\checkmark$ \\
\hline Honey kinds text & Text information & - & & $\checkmark$ \\
\hline
\end{tabular}

\section{Conclusions}

Agricultural products quality safety becomes the hot topic which the people at home and abroad generally pay attention to in recent years. As ways of guaranteeing quality safety, tracing and tracking technology have been widely used in the developed countries such as America, Canada, Japan, New Zealand and so on. In recent years Chinese government has been paying much more attention to food quality safety and also has done a lot of work for quality safety and traceability. As the largest beekeeping country in the world, beekeeping is Chinese traditional industry, in addition honey is important traditional product of foreign exchange income. So how to use tracing and tracking technology to further strengthen bee product safety control and management is an urgent affair. On the basis of analyzing the present situation of Chinese bee product quality safety, this paper proposes developing bee product traceability platform and barcode system and finally realizes bee product general quality control.

1) This paper first analyzes bee product quality safety status and research situation of bee product traceability system. We should develop bee product traceability barcode system and quality safety platform which are suitable for Chinese situation.

2) Secondly based on GS1 system we respectively encoded in four links of bee products circulation. Unique and standardization bee product barcode system are used in traceability platform.

3) Finally we developed agent-based bee product quality traceability platform which could realize farm-to-table traceability. 


\section{Acknowledgments}

This research was supported by the National Natural Science Foundation of China (Grant No.60972154).

\section{References}

1. Li, S., et al., Status quo of quality safety of bee products and construction of whole-process traceability system. Nongye Gongcheng Xuebao/Transactions of the Chinese Society of Agricultural Engineering, 2008. 24(SUPPL. 2): p. 293-297.

2. Zhu, Y.P., et al., Design of bee products quality monitoring information service platform. Computer and Computing Technologies in Agriculture ii, volume 3, 2009: p. 2141-2149.

3. Liu, S., Y. Zhu and S. Li. Research on data acquisition system for agent-based bee product traceability platform. 2010 World Automation Congress, WAC 2010, p 375-381.

4. Zhu, Y., et al. Agent-based bee product quality control system. 2nd International Conference on Data Mining and Intelligent Information Technology Applications, 2010, p 346-350.

5. Zhu, Y., et al. Design of agent-based agricultural product quality control system. IFIP Advances in Information and Communication Technology, v 344 AICT, PART 1, 2011, p 476-486.

6. Borkovcova, I., et al., Quality and safety of Czech honey. Acta Scientiarum Polonorum Medicina Veterinaria, 2008. 7(4).

7. Casillas, P. and G. Echazarreta, Factors that influence the quality and safety of honey. Revista Chapingo. Serie Ingenieria Agropecuaria, 2002. 5(1/2).

8. Mahaman, B.D., et al., A diagnostic expert system for honeybee pests. Computers and Electronics in Agriculture, 2002. 36(1): p. 17-31.

9. Montet, D., et al., Future topics of common interest for EU and SEA partners in food quality, safety and traceability. Quality Assurance and Safety of Crops \& Foods, 2010. 2(4): p. 158164.

10.Yue, E., Y. Zhu and Y. Cao. Multi-agent quality of bee products traceability model based on roles. IFIP Advances in Information and Communication Technology, v 345 AICT, PART 2, 2011, p 110-117.

11.Zheng, H., et al., Construction of traceability system for quality safety of cereal and oil products. Scientia Agricultura Sinica, 2009. 42(9): p. 3243-3249.

12.Liu, S., et al., Study on quality safety traceability systems for cereal and oil products. 2009 WRI World Congress on Software Engineering, Vol 1, Proceedings, 2009: p. 163-166.

13.Pouliot, S. and D.A. Sumner, Traceability, liability, and incentives for food safety and quality. American Journal of Agricultural Economics, 2008. 90(1): p. 15-27.

14.Zhu, Y.P., et al., Agriculture and forestry economy decision support system based on agent. New Zealand Journal of Agricultural Research, 2007. 50(5): p. 1339-1346.

15.Zhu, Y., Z. Feng and Y. E, Application of Agent in agricultural expert system inspection software. Scientia Agricultura Sinica, 2006. 39(8): p. 1553-1557.

16.Zhu, Y., S. Li and E. Yue, Application of the agent in agricultural expert system inspection software. Agricultural Sciences in China, 2008. 7(1): p. 117-122.

17 R. H. Bordini, M. Wooldridge, and J. F. Hübner, Programming multi-agent systems in agentspeak using Jason (Wiley Series in Agent Technology), John Wiley \& Sons, 2007.

18 R.H. Bordini, M. Fisher, W. Visser, and M. Wooldridge, "Verifying Multi-Agent Programs by Model Checking", J. Autonomous Agents and Multi-Agent Systems, 2006, 12(2), p. 239-256. 